\title{
A sublime beleza do eterno perecível
} Sebastiana Fadda

\begin{abstract}
Titulo: 0 retrato de Dorian Gray. Autor: Oscar Wilde. Tradução: Margarida Vale de Gato. Dramaturgia e encenação: Bruno Bravo. Música: Sérgio Delgado. Cenário e figurinos: Stéphane Alberto. Interpretação: António Mortágua, Carolina Salles, Paulo Pinto, Ricardo Neves-Neves e Sandra Faleiro. Participação especial: Eduardo Molina, Francisco Sousa, Ivone Fernandes, Joana Campelo, Lia Carvalho, Madalena Flores, Mário Mendes, Sandra Pereira, Thomas Mendonça e Victor M. Gonçalves. Desenho de luz: Roger Madureira. Apoio vocal: Joana Campelo. Fotografias e vídeos: Promocionais Eduardo Breda. Execução dos figurinos: Sandra Ferreira. Direcção de produção: Paula Fernandes. Co-produção: Primeiros Sintomas / ZdB. Local e data de estreia: Negócio/ZDB, Lisboa, 23 de Abril de 2014 [estreia da primeira parte: Ribeira, Lisboa, 18 de Setembro de 2013; versão integral posteriormente apresentada no Teatro Municipal Joaquim Benite, Almada, 16 e 17 de Maio de 2014].
\end{abstract}

As coisas são o que são, mas também o que parecem. As coisas não são o que são, nem o que parecem. As coisas em si não são, apenas são em nós. As coisas são o contrário do que parecem. 0 que parece é o contrário do que é. Ou apenas, as coisas são o que são e serão o que serão. Qual a distância entre a especulação filosófica e a tautologia mais banal? "Nós somos o que somos e seremos o que seremos", dirá a certa altura Lord Henry Wotton a Dorian Gray. Exemplo de tautologia ligeira e snob ou absoluta e definitiva?

Por certo, é para o território da especulação brilhante da literatura inovadora, da confluência e afirmação de gostos e estéticas que colidem com o tempo austero e a sociedade hipócrita em que surgiu, que nos convida $O$ retrato de Dorian Gray, enquanto realça todo o génio do seu autor. Fascinantes, a sua escrita e as suas personagens são feitas de matéria dúctil e polissémica, esculpidas com despudorada liberdade criativa, fértil imaginação e eloquência requintada. Consta que o autor tenha afirmado, numa carta datada de 12 de Fevereiro de 1894 dirigida a Ralph Payne:

A longa série foi

inaugurada pelo filme dinamarquês Dorian Grays

Portreet, do realizado

Axel Strøm (1886-1950): em 1913 éa vez de Dorian

Gray Portrait, do

realizador Phillips Smalley (1865-1939), primeira de

muitas versões

norteamericanas; em 1915

segue uma produção

russa, Portret Doryana

Greya, realizada po

Vsevolod Meyerhold

(1874-1940) e Mikhail

Doronin (1880-1939);

em 2009 chega às salas

Dorian Gray, na adaptação

do britânico Oliver Parker

(1960)
Estou tão contente que você goste desse meu livro colorido e estranho: ele tem muito de mim mesmo. Basil Hallward é o que eu penso que sou; Lord Henry é o que o mundo pensa de mim; Dorian o que eu gostaria de ser, noutras épocas, talvez. (Wilde apud Dawson 1990; tradução minha)

Será, no entanto, primário e redutor fazer uma leitura meramente autobiográfica do romance, porque é, em primeira instância e para todos os efeitos, pelas suas qualidades intrinsecas que se tem afirmado entre as obrasprimas da literatura universal. Para além de inúmeras versões nas mais diversas línguas - várias encontram-se disponiveis em português -, o romance inspirou também muitas traduções intersemióticas, tendo havido mais de duas dezenas de produções cinematográficas e televisivas desde $1910^{1}$ até aos nossos dias.

0 que aqui convoca aquela fonte é a transcrição recente para o palco oferecida pelos Primeiros Sintomas, que já tinham, de resto, visitado o universo dramático de Oscar Wilde com Salomé, justamente distinguida em 2012 com uma Menção Especial pela Associação Portuguesa de
Críticos de Teatro. Se várias das oportunas apreciações de João Carneiro a respeito desse espectáculo (Carneiro 2013 19-20) se demonstram adequadas também a 0 retrato de Dorian Gray, sendo este uma continuação do discurso artístico aberto por aquele, não será de todo descabido perguntarmo-nos, no entanto, o que é este objecto que agora nos é apresentado? Que relação mantém com o original e de que modo dialoga a dimensão horizontal e plana da página com a dimensão vertical e tridimensional do espaço cénico?

Nem sempre as perguntas são retóricas. Não o são quando nos obrigam a reflectir para encontrar respostas que provavelmente levam a outras perguntas. Porque a conclusão a que se chega é que estamos perante um artefacto - no sentido etimológico do termo: algo feito com arte - aberto, que propõe e sugere, sem prescrever ou impor um ponto de vista unívoco, nem enclausurar significações, rumos ou possibilidades. Para que isso aconteça é decisiva a inteligente e sensivel operação dramatúrgica efectuada pelo encenador, que não ambicionou lançar-se numa impraticável competição com o romance (na bela reescrita de Margarida Vale de Gato). $\mathrm{Na}$ impossibilidade de se comparar ou substituir o acto da leitura, e respectiva encenação mental, que cada leitor pode praticar em solidão, o encenador conseguiu sugerir uma ambiência densa, simbólica e envolta em mistério. Dito com uma metáfora: não cabendo num palco o jardim inteiro, Bruno Bravo tentou trazer das flores o seu perfume.

De início, o espaço cénico está quase despido, a não ser pela presença de um candeeiro de cristal, uma mesa aprontada com bule e chávenas de porcelana, tão típicos do país do famoso "chá das cinco". Surgem os actores, elementos que apontam para o exterior, uma cadeira e um banco de metal, um regador, enquanto se ouve o barulho dum coche em andamento, o canto dos pássaros e música bucólica a condizer.

Estamos no jardim de abertura do romance e os actores dão corpo ao narrador - com vozes por vezes em sincronia, outras assíncronas, em ligeiro desfasamento, criando ecos -, e estabelecem, assim, de imediato a ligação umbilical entre literatura e teatro. Outras explicitações desse laço são reconhecíveis noutros momentos, como 


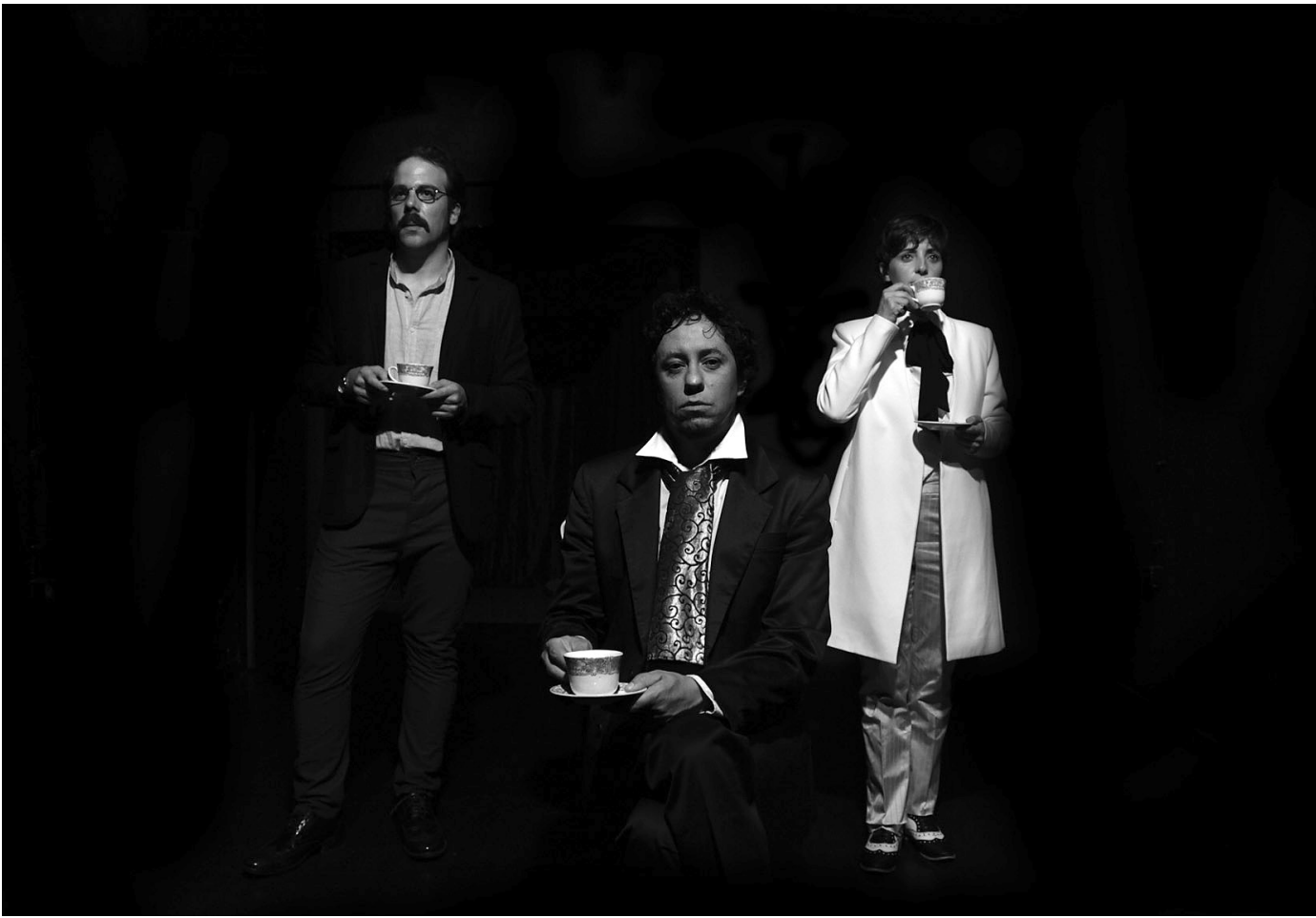

O retrato de Dorian Gray de Oscar Wilde,

dramaturgia e enc. Bruno Bravo, Primeiros Sintomas 2013 (António Mortágua Paulo Pinto e Sandra Faleiro), fot. Eduardo Breda. [Foto de ensaio da $1^{\text {a }}$ versão.] por exemplo quando, na segunda parte, Dorian descreve com fúria exaltada a decoração da sua mansão, os retratos, os retratados e todos os sinais de luxo, luxúria e corrupção doentia que o rodeiam, inflamando o seu desejo de transpor todos os limites, sejam eles impostos pela natureza ou pela sociedade. Ou então quando lê em silêncio o livro enviado por Lord Wotton, ambos mais tarde acusados de serem os responsáveis pelo seu envenenamento moral, com uma voz em off que the empresta o som, tendo-se evitado o expediente mais usual e de tentação óbvia: a leitura em voz alta pelo próprio intérprete/leitor em cena. E é também mais literário, musical, dramático e performativo o momento coral em que os figurantes criam uma espécie de caixa de ressonância amplificadora - em crescendo inquietante do delirante solo estético-hedonístico de Dorian Gray?

Do enredo ficou o essencial: as personagens e o seu traço mais marcado. 0 pintor Basil Hallward (António Mortagua), artista fascinado pelo seu modelo, entrega-se sem reservas no retrato que pinta, por isso nunca poderá expô-lo, pois exibiria a nudez da sua alma. Lord Henry Wotton (Paulo Pinto), hedonista devoto do belo, bon vivant de raro engenho e sagacidade, curioso de conhecer a criatura que desperta emoções tão apaixonadas, tornarse-á seu mentor. Dorian Gray (Sandra Faleiro), o modelo que descobre a sua beleza espelhando-se nos olhos dos outros, como Narciso enfeitiçado pela sua imagem, como Fausto renuncia à alma, que, pela força do desejo, milagrosamente se transfere para o quadro, em que é a sua imagem que envelhece, enquanto o corpo mantém uma aparência incorrupta pelo tempo. Sybil Vane (Carolina Salles), cândida actriz adolescente, confunde o teatro com a vida, dai ser credivel em palco e encantar Dorian Gray, que troca a verdade do artifício pela arte. Incapaz de recitar quando descobre o amor desse "principe encantado", que a abandona pela sua inépcia, ela torna-se incapaz de viver sem amor, ficando sem arte em cena e sem papel no mundo, acabando por se suicidar. James Vane (Ricardo
Neves-Neves), irmão da menina frágil, tão desamparado quanto ela, pertence às pessoas comuns que, quando muito, poderão ser heróis em imaginários "melodramas ridiculos", mas não passam de uma humanidade invisivel "para os elegantes" que passeiam nos parques e frequentam os teatros.

Muito longe levaria o aprofundamento das fontes inspiradoras, directas e indirectas de 0 retrato de Dorian Gray, bem como das correntes estéticas, filosóficas, literárias e psicanalíticas, e das respectivas teorias, que 0 texto levanta a todo o instante. Porém, vale a pena referir aqui algumas considerações, mais presas à dramaturgia da representação. Uma, talvez central, envolve a Arte enquanto conceito, objecto constantemente evocado nas falas das personagens masculinas:

- Basil cria a sua obra-prima, agarra a alma do seu modelo, mas também põe (e perde) a sua alma na sua arte, pelo que depois disso só será capaz de pintar vulgaridades; perde também a vida, ao não conseguir libertar-se das suas obsessões;

- Dorian, pelas artes (plásticas) de Basil e (da eloquência) de Lord Wotton, confunde e troca arte e artifício; por efeito da juventude (imaturidade) ignora a existência da alma; por efeito do tempo (experiência) (re)conhece-a quando já a desbaratou;

- Lord Wotton é um esteta e um hedonista que enaltece e segue os princípios da beleza e do prazer; para ele a arte "é superior à realidade", "está acima da moral", basta-Ihe "curar os sentidos através da alma e a alma através dos sentidos", o resto deixa-o ao cuidado, ou ao desleixo, dos mediocres.

Emblemática, a personagem feminina é o oposto complementar que esclarece ou ilumina certas afirmações do seu interlocutor. Sybil é a alma que se descobre no amor. Antes de conhecer Dorian, representar era a única coisa real na sua vida. Ele mostrou-Ihe a realidade da vida e 0 artifício da representação, por isso já não podia fingir. 
retrato de Dorian Gray,

de Oscar Wilde,

dramaturgia e enc. Bruno Bravo, Primeiros Sintomas, 2013 (António Mortágua),

fot. Eduardo Breda. [Foto de ensaio da $1^{3}$ versão.]

0 retrato de Dorian Gray, de Oscar Wilde, dramaturgia e enc. Bruno Bravo, Primeiros Sintomas, 2014 (Sandra Faleiro), fot. Eduardo Breda. [Foto de ensaio da versão integral.]

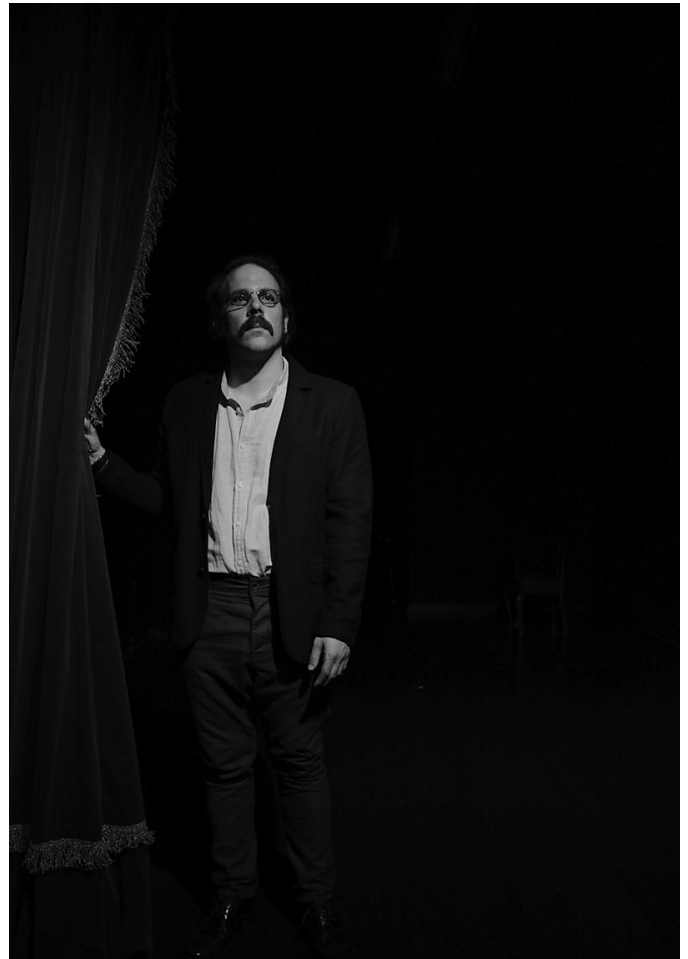

Mas essa Sybil (verdadeira) matou o amor (falso) naquele que era um artificio (por não ter alma). "0 que és tu sem a arte?", pergunta-Ihe, desumano. Chocada, Sybil acorda da ilusão de ter pensado encontrar a alma gémea e, rejeitada prefere morrer. Só então, heroína trágica, eleva-se acima das vacuidades e falsidades do palco e da vida, fazendo da vida e da morte uma arte, porque sempre acreditara, com toda a sua alma, ora numa ora noutra. Aos olhos de Dorian Gray e Lord Wotton, para quem "não há nada que a arte não possa exprimir" por ser "uma pálida imagem da realidade", tão frivolamente, "a vida é tão

extraordinariamente dramática", pelo que aquela morte não passa dum "final magnífico... numa peça magnífica": bela literatura melodramática.

As personagens masculinas principais - em triangulação constante - revelam-se cultas apreciadoras do pensamento abstracto e das especulações filosóficas e intelectuais. 0 elemento mais fraco é o pintor, que tem ideais artísticos, mas também princípios éticos, diferente, portanto, dos que adoptam por credo a primazia da arte sobre a vida e a volúpia dos estetas. A requintada atmosfera cultural, homoerótica e discreta ou heterossexual e imatura, é o pano de fundo onde decorre uma conversação erudita modulada em frequências variáveis, mantida sempre em tons elevados: distraida, sentenciosa, amena, irónica, sarcástica, altaneira, cínica, imperativa, cheia de aforismos.. Se as muitas nuances identificam as atitudes mentais ou os estados emocionais dos falantes, as personagens, cinzeladas com minúcia pelo autor, que assim comprova a sua grande capacidade de observação da vida e da alma humana, encontraram os intérpretes certos nos actores que as encarnaram. Pondo a tónica dominante num adjectivo capaz de caracterizar o seu trabalho, uma "altiva" Sandra Faleiro compôs um Dorian Gray admirável, um "espirituoso" Paulo Pinto deu leveza e distinção a Lord Wotton, um "sombrio"António Mortágua transmitiu as lides cerebrais e animicas de Basil, uma "desarmante"

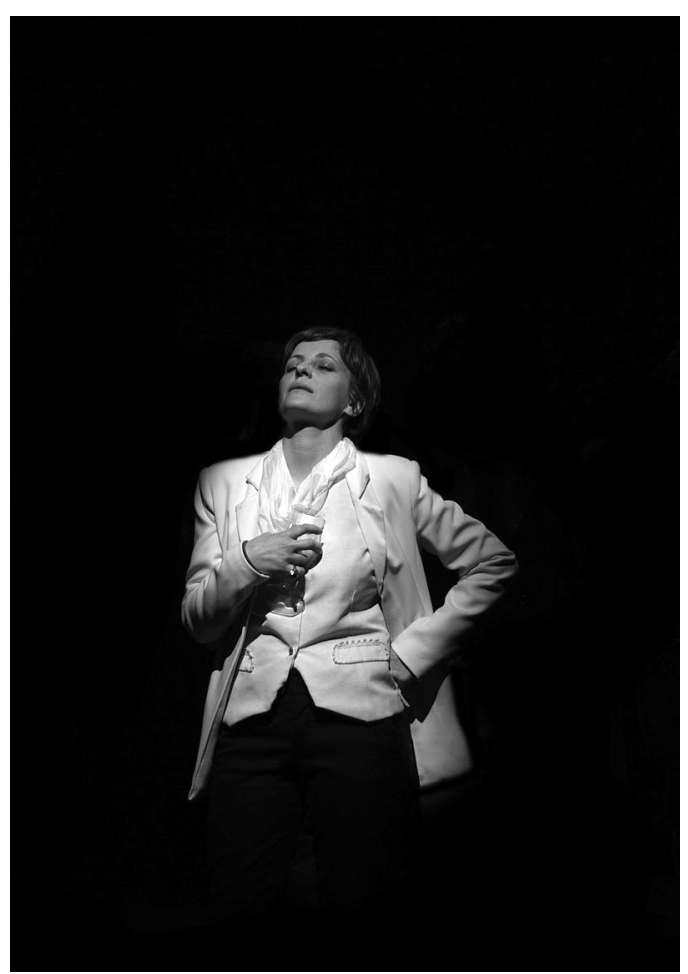

Catarina Salles como Sybil e um "ingénuo" Ricardo NevesNeves como James mostraram a distância do seu universo em relação ao dos demais. Perfeitos também os figurantes, discretos, silenciosos e imprescindiveis. As marcações, rigorosas, por vezes procuravam o equilíbrio de geometrias simétricas, com as personagens que estacavam, ficando estáticas por alguns segundos, interrompendo o fluir duma acção, posando para instantâneos fugidios, retratos vivos no Retrato, emoldurados por uma iluminação cuidada.

Sóbrios e elegantes, o cenário e os figurinos de Stéphane Alberto apostaram numa grande economia de meios e na eficácia do seu simbolismo cromático. 0 cenário, na primeira parte, apresenta poucos adereços, algumas peças de mobiliário em estilo arte nova ou de metal para jardim, destacando-se do fundo negro que se presta à dupla espacialidade de interior e exterior. Na segunda parte, a dupla espacialidade mantém-se, mas remete para um lugar físico e outro mental: um relógio de caixa alta, um canapé em madeira de dois lugares, as paredes forradas de cortinados vermelhos (um reposteiro, de veludo da mesma cor, com galão dourado e de franjas, vindo da Salomé), decoram a sala de Dorian Gray, mas também aludem à intima degradação da sua consciência.

Os figurinos ficam quase inalterados ao longo da representação. Dorian Gray sobressai soberbo e distante na sofisticação do seu traje claro, em vários tons de branco, com casaco curto, colete, luvas, elaborado laço ao pescoço, calças às riscas muito finas num tom um tudo nada mais escuro, que harmonizam com o todo criando uma ligeira transição até chegar ao cinzento escuro dos sapatos. Só as luvas é que deixarão de ser utilizadas, quando o modelo se humaniza. Lord Wotton veste um fato numa nobre e caprichosa cor beringela, com écharpe acetinada prata, como em prata é o castão da bengala que usará mais tarde para assinalar a passagem do tempo e o desgaste do corpo. Mais informal apresenta-se Basil Hallward, de camisa vermelho-alaranjada, calças cinza e suspensórios pretos, 


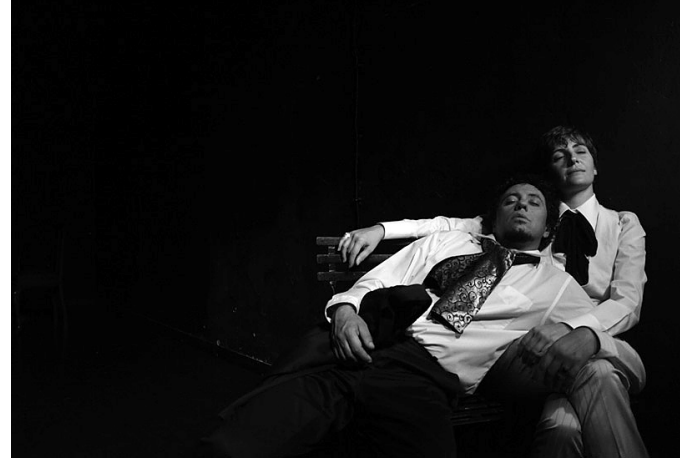

usando óculos que dão um ar grave ao seu ser atormentado. Preto total para os dez figurantes, vestidos a rigor com fatos de cerimónia - casaca, fraque, blazer de abotoamento duplo -, que representam as aparições fantasmáticas que povoam a mente de Dorian Gray. Sybil é a única personagem que se transforma, como evidenciam os seus figurinos: de robe vermelho-lascivia no camarim do teatro, enquanto retira a maquilhagem de cena, máscara que mal disfarça um rosto de criança que olha espantada para o mundo: de sapatinhos encarnados com tirinha, e fresco vestido cor de pêssego, de menina-mulher a desabrochar para as promessas da vida, quando confia os seus sentimentos ao irmão; de vestido branco comprido e coroa de flores na cabeça, quando, Julieta falhada, envergonha Dorian perante os seus amigos e é repudiada. Sem ela o saber, está prestes a brilhar no papel de virgem-noiva da morte.

Poderosa e apropriada, a banda sonora de Sérgio

Delgado, pelos trechos seleccionados, indicia a composição dum majestoso Requiem. 0 efeito foi a criação de ambientes habitados por emoções quase palpáveis:

- discretas e complementares da acção, reforçada pelas "Cenas da floresta" de Schumann ou pelo nocturno de Chopin;

- solenes e dominantes, como no caso da assombrosa ária "Let me freeze again to death", cantada pelo Génio do Frio no King Arthur de Purcell, sobre libreto de John Dryden (a solução de transformar a versão gravada, de Andreas Scholl, num dueto, com a intervenção expressiva de Mário Mendes ao vivo, conferiu-Ihe especial intensidade);

- tristes e tocantes, como aquela introduzida pela Lamentação de Dido, na estupenda ária "When I'm laid in earth", do Dido and Aeneas, também de Purcell e libreto de Nahum Tate, na entoação compenetrada, doce e pesarosa de Joana Campelo.

De novo, ao dialogar com Oscar Wilde, Bruno Bravo envereda pela via poética do inefável, deixando implícito o pressuposto inicial, mantendo em aberto o espectáculo inclusive no seu "epílogo", de acordo com a estética que o norteou, optando por interromper a sua leitura antes do fim do livro.

O seu Dorian não mata James, nem precisa de se apunhalar no retrato para que, ele que estava perdido na mentira, ou que nunca chegara a achar-se na amoralide, se reencontrar consigo próprio na verdade. A peça suspende o romance na altura em que o ex-modelo de perfeição, depois de se ter manchado com o sangue de Basil e de se ter precipitado na abjecção, encara a sua própria consciência. Afinal, feito Rei Midas ao avesso, transformara em podridão tudo aquilo em que tocou. A fealdade, esculpida e tatuada na pele e na alma através das acções e sentimentos, ficou

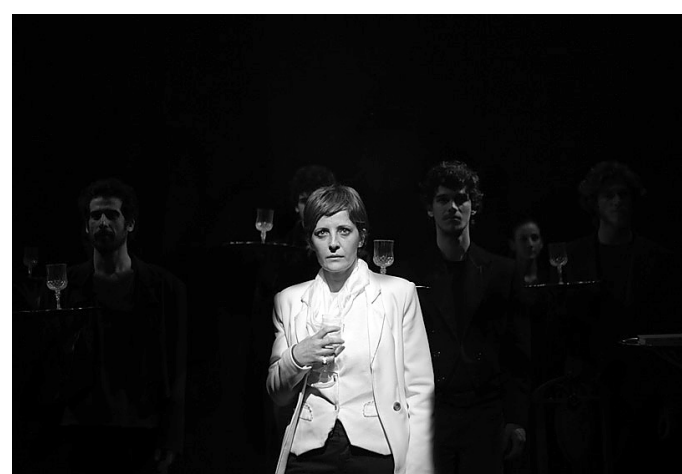

O retrato de Dorian Gray de Oscar Wilde, dramaturgia e enc. Bruno Bravo, Primeiros Sintomas 2013 (Paulo Pinto e Sandra Faleiro), fot. Eduardo Breda. [Foto de ensaio da $1^{\text {a }}$ versão.]

denunciada pelo quadro. Ao dizer "vou mudar", em tom quase neutro, como dantes mostrara a distância perante a beleza, devorando a vida alheia, mostra a frieza perante o repelente: (des)conhece-se a si próprio no ser em que se tornou.

Este Dorian permite uma interpretação inesperada: ele acorda para a essência das coisas e para a dimensão do tempo, que discrimina e separa, para questões ligadas à prática do bem e do mal. Finalmente percebe. A beleza aparente de nada serve: o quadro lá estava, para Ihe recordar aquele que era e aquele em que se tornara, revelando que a Beleza não habitava nele. Ao resolver mudar, já homem (des)feito e experimentado, compreende que deve aceitar o tempo e a finitude, a humanidade perecivel e perene, enquanto dura. Ao aceitar a mudança, ele deixa morrer ainda em vida - no espaço mais íntimo da sua consciência reencontrada -, o homem corruptivel e corrupto que foi. Desperta para outra Beleza. A que morre e renasce a cada instante, eterna e efémera. Haverá quem Ihe chame Alma.

A Alma não se vende. Não tem preço e não se troca. A Beleza da Juventude vem da Alma, mesmo que (in)consciente. A Juventude sem Alma não tem Beleza. A Beleza está para além da Juventude. Não há Beleza sem Alma. Onde há Alma há Beleza. Novas tautologias. Mas a Alma é, ou se constrói, talvez e também, com acções que não geram infelicidade. Não por questões morais e sociais convencionais e impostas, mas éticas e intimas escolhidas em consciência e liberdade.

Isto tem a ver, ainda, com a responsabilidade do artista que, para além de indagar a essência da sua arte, formula perguntas fulcrais, como, por exemplo: o que significa, como pode existir, ou como se concilia, a Beleza e o Verdadeiro? E ainda: como fazer coincidir a Vida com a Arte, a Beleza com o Verdadeiro? Que fazer deles? Haverá, de novo, quem lhe chame Alma? Ficam as perguntas e um epitáfio idealista para Basil: a Beleza é, não mente, não aparenta ser, nem morre nunca.

\section{Referências bibliográficas}

CARNEIRO, João (2013), "A Salomé, de Bruno Bravo: Um espectáculo de poesia", in Sinais de cena, APCT / CET, n. ${ }^{19}$, Junho, pp. 19-20.

DAWSON, Terence (1990), "Fear of the Feminine in the Picture of Dorian Gray", Psychoanal. Review, Summer, vol. 77(2), pp. 263-80 (ref. indirecta, fonte consultada: "Fear of the Feminine-Private in the Picture of Dorian Gray", no sitio:

http://www.victorianweb.org/authors/wilde/dawson1.html [data de acesso: 20 de Maio de 2014]).
O retrato de Dorian Gray de Oscar Wilde dramaturgia e enc. Bruno Bravo, Primeiros Sintomas 2014 (Sandra Faleiro, ao centro; figurantes, da esqerda para a direita: Francisco Sousa, Eduardo Molina, Mário Mendes, Lia Carvalho e Thomas Mendonça), fot. Eduardo Breda [Foto de ensaio da versão integral.] 